\title{
Analysis of Adherence to Antihypertensive Drugs in Chinese Patients with Hypertension: A Retrospective Analysis Using the China Health Insurance Association Database
}

This article was published in the following Dove Press journal:

Patient Preference and Adherence

\author{
Bin Cui $\mathbb{D}^{1}$ \\ Zhaohui Dong ${ }^{2}$ \\ Mengmeng Zhao ${ }^{3}$ \\ Shanshan $\mathrm{Li}^{4}$ \\ Hua Xiao ${ }^{4}$ \\ Zhitao $\mathrm{Liu}^{4}$ \\ Xiaowei Yan $^{5}$ \\ 'School of Public Health, Peking \\ University, Beijing I00191, People's \\ Republic of China; ${ }^{2}$ Human Resources \\ and Social Security, Chinese Academy of \\ Labour and Social Security, Beijing, \\ 100029, People's Republic of China; \\ ${ }^{3}$ School of Pharmaceutical Science and \\ Technology, School of Pharmacy, Tianjin \\ University, Tianjin, 300072, People's \\ Republic of China; ${ }^{4}$ Medical Affairs, Bayer \\ Healthcare Company Limited (China), \\ Beijing, 100020, People's Republic of \\ China; ${ }^{5}$ Department of Cardiology, \\ Peking Union Medical College Hospital, \\ Beijing, 100730, People's Republic of \\ China
}

Correspondence: Xiaowei Yan Peking Union Medical College Hospital, Beijing 100730, People's Republic of China Email yanxiaowei2019@gmail.com
Objective: To analyze the adherence to antihypertensive drugs in Chinese patients with hypertension and the factors associated with the drug adherence.

Methods: The data for this analysis were obtained from the 2014 China Health Insurance Association (CHIRA) database. The study included 64,576 patients aged $\geq 18$ years who were prescribed one of the seven antihypertensive drugs included in the study in their first prescription in 2014 and were observed for $\geq 180$ days. The medicine possession ratio (MPR) was calculated and taken as the measure of treatment adherence. MPR values $<0.3,0.3$ to $<0.5,0.5$ to $<0.8$, and $\geq 0.8$ were considered treatment adherence very low, low, intermediate, and high, respectively. Descriptive statistics were used to present baseline data and treatment adherence rate. Multiple regression models were used to determine independent factors which can affect the treatment adherence rate. $P$-value $<0.05$ was considered significant.

Results: Among the study antihypertensive drugs, amlodipine (33.98\%), metoprolol (25.04\%), and nifedipine (17.15\%) were the frequently prescribed drugs. Nifedipine controlled release tablet had the highest MPR (0.61), followed by valsartan (0.53), valsartan/ amlodipine fixed-dose combination (0.50), indapamide (0.40), and amlodipine (0.39), whereas benazepril (0.27) and metoprolol (0.19) had the lowest MPR. Higher reimbursement ratio, regular tertiary hospitals visits, lower age, and lower daily medical cost positively affected treatment adherence, whereas longer duration of illness and higher daily average cost affected treatment adherence negatively.

Conclusion: Our study assessed that prescribing more cost-effective, long-acting antihypertensive drugs, and raising the reimbursement ratio were associated with a better treatment adherence in Chinese patients with hypertension.

Keywords: treatment adherence, medicine possession ratio, hypertension, antihypertensive treatment

\section{Introduction}

Hypertension (HTN) is the most prevalent and preventable risk factor for cardiovascular diseases (CVDs) and CVD-related mortality. ${ }^{1}$ It majorly accounts for global allcause mortality; 10.5 million deaths in 2016 were related to elevated systolic blood pressure. $^{2,3}$ The global burden of hypertension data (1990-2015) of population with systolic blood pressure $110-115 \mathrm{mmHg}$ revealed that globally, approximately one in every four adults is suffering from HTN. ${ }^{1}$ In addition, a survey conducted between 
2012 and 2015 showed that in China, $23.2 \%$ of total population aged $>18$ years had HTN, whereas $41.3 \%$ had preHTN. ${ }^{4}$ Clinical studies have shown that efficient HTN control $(<140 / 90 \mathrm{mmHg}$ ) reduces CVD- and stroke-associated morbidity and mortality. 5,6

Although several classes of antihypertensive (AHT) drugs are available and prescribed as per the guidelines to control HTN, ${ }^{7-10}$ their effectiveness is detrimentally affected by poor treatment adherence, which results in increased mortality, cardiovascular morbidity, rate and length of hospitalization, overall medical expenditure, and exacerbated quality of life. ${ }^{11-14}$ The World Health Organization defines adherence as

the extent to which a person's behavior-taking medication, following a diet, and/or executing lifestyle changescorresponds with agreed recommendations from a healthcare provider. ${ }^{15}$

Nonadherence to AHT medication has become a global cause of concern as it adversely affects the efforts made by healthcare professionals and policy makers to control HTN. ${ }^{16}$

Previously, treatment adherence was investigated using pill counts, clinical reports, prescriptions, and patientreported information. ${ }^{17}$ However, in recent years, new preferred approaches to measure treatment adherence have been developed, including patient-reported questionnaires, scales, medicine possession ratio (MPR), and proportion of days covered. ${ }^{17} \mathrm{MPR}$, defined as the percentage/proportion of days' supply obtained until the last refill (refill interval) or a specific time period (fixed refill), ${ }^{18,19}$ is an established measure of AHT treatment adherence. ${ }^{20-22}$ It is generally $<1$; however, may exceed 1.0 if the patients obtain refills prior to their supply running out. ${ }^{23}$ Despite a few limitations (eg, nonavailability of clinical data, etc), pharmacy databases managed by a health-care organization, private as well as government insurance companies serve as a good source of data for evaluating treatment adherence, as they provide "real-world" evidence and the data can be easily retrieved for analysis. ${ }^{18,24}$

Several studies have analyzed adherence to AHT drugs in different regions of the world. ${ }^{11,16,25-28}$ However, there is scarcity of evidence on AHT treatment adherence among the Chinese population in real-world settings. ${ }^{25,29}$ Ethnic diversity is reported to affect pharmacological actions of AHT drugs, ${ }^{30}$ and regional/cultural differences in health care may influence AHT drug-taking behavior of patients with HTN. ${ }^{31}$ This limits the application of treatment adherence information of one geographical region to another in true sense. Therefore, we evaluated AHT treatment adherence, in terms of MPR, and the factors affecting MPR of the seven most commonly used AHT drugs among the Chinese population in real-life settings using information extracted from the China Health Insurance Association (CHIRA) database.

\section{Methods}

\section{Study Design}

This was a retrospective analysis of data of patients with HTN taken from the CHIRA database for 2014. The CHIRA database had data of 6,560,000 patients from 77 cities, of which, data of 3,344,000 patients were excluded due to lower/missing outpatient diagnosis rate and/or higher diagnosis missing rate (Figure 1). Employee medical insurance data of 33 cities with relatively high quality (including outpatient and inpatient data) were used for the analysis.

Patients with clinically diagnosed HTN and aged $\geq 18$ years were included in the analysis if their first prescription for 2014 had any of the following AHT drugs: benazepril, an angiotensin-converting enzyme (ACE) inhibitor; valsartan, an angiotensin receptor blocker (ARB); metoprolol, a $\beta$ blocker; nifedipine and nifedipine gastrointestinal tablets (GITs), a calcium channel blocker (CCB); amlodipine, a CCB; indapamide, a diuretic; or valsartan/amlodipine fixed-dose combination (FDC). Patients covered by employee medical insurance and patients with hypertension caused by secondary diagnosis were also included in the study. Of these patients, only those who were prescribed AHT drugs at least or more than twice were observed for $\geq 180$ days (first prescription-last prescription) were included in the analysis. Patients with cancer, organ failure, and gestational/postoperative HTN were excluded from the analysis. The successive prescriptions were used to analyze treatment adherence. During the data extraction step, data on member eligibility (demographics); inpatient medical informationadmission date/discharge date; place of service including hospital tier (tier 1, primary care hospitals; tier 2, city-level hospitals; tier 3, teaching hospitals); type, and department; length of stay; primary diagnosis according to International Classification of Disease (ICD)-10/Chinese texts; and diagnosis description); and outpatient medical informationdate; place of service including hospital tier; type, and department; and primary diagnosis (ICD-10/Chinese text); services claims (drug name, drug code; prescription, examination, treatment, operation, bed, medical materials, etc; drug unit price; drug formulations; and dispensed quantity of drug), cost of each event, and other relevant information was extracted. The data for cities with outpatient diagnosis 


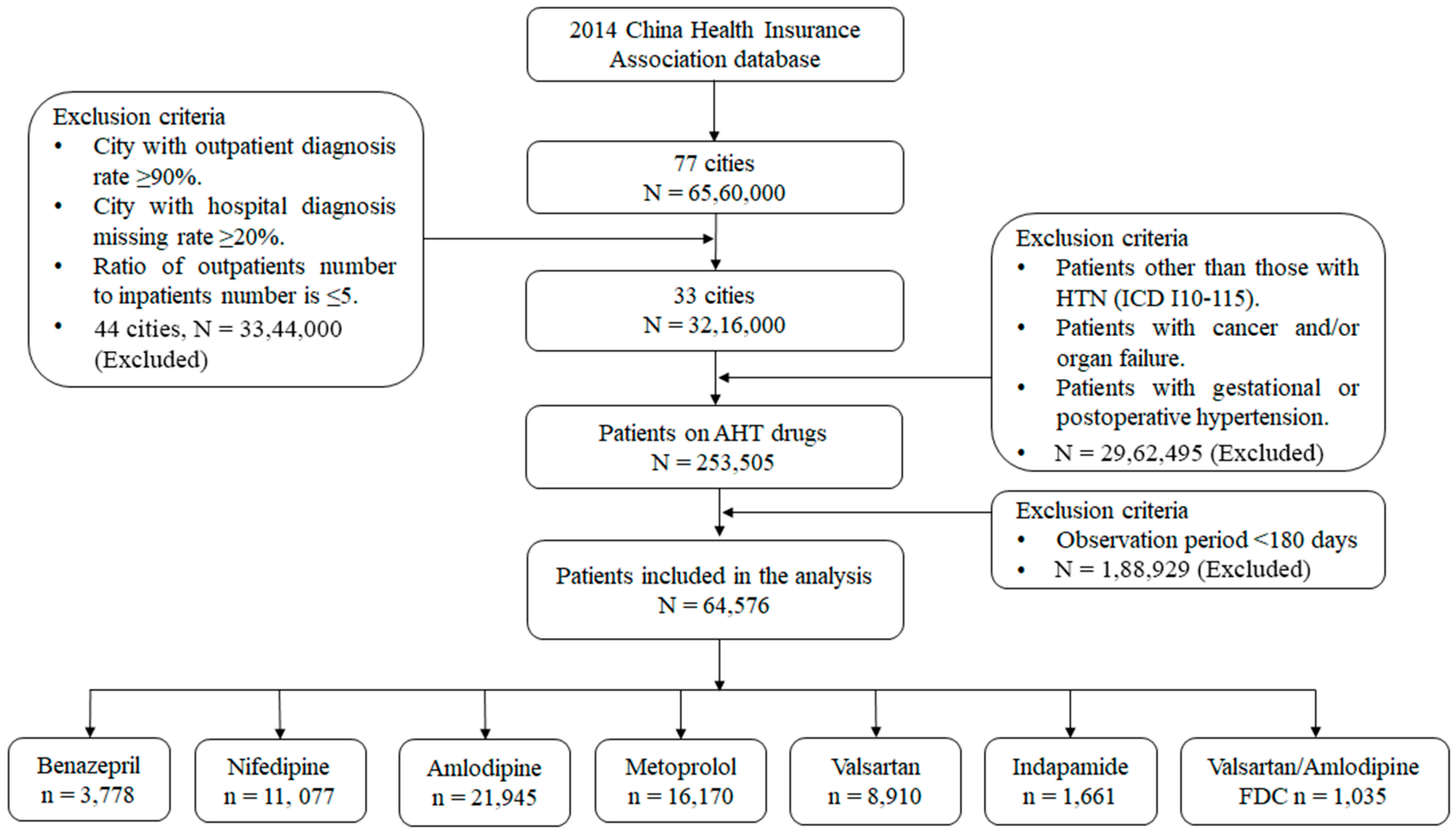

Figure I Study flow diagram.

missing rate of $\geq 90 \%$, hospital diagnosis missing rate of $\geq 20 \%$, and the ratio of outpatients number to inpatients number is $\geq 5$. After excluding patients other than those with ICD 10 I10-115 HTN, patients with organ failure and/ or cancer and/or gestational/postoperative HTN, 64,576 patients (mean age: 63.4 years; males: 51.73\%; females: $48.27 \%$ ) were included in the analysis.

The study was conducted in accordance with the Guidelines for Good Pharmacoepidemiology Practice, ${ }^{32}$ Good Practice of Secondary Data Analysis, ${ }^{33}$ the European Network of Centers for Pharmacoepidemiology and Pharmacovigilance Guideline on Methodological Standards in Pharmacoepidemiology, ${ }^{34}$ and Good Epidemiological Practice. $^{35}$

\section{End Points}

Measuring treatment adherence among study populations in terms of MPR was the primary end point of the study. The secondary end points were hospital visits and determination of the factors affecting treatment adherence.

For 2014, MPR was calculated as total days' supply of drug dispensed (excluding the last prescription) during the year divided by total days from the first prescription until the last prescription given during the observation period. Total drug supply for each study drug was calculated as the total amount of drug prescribed in 2014 divided by defined daily dose. Observation period was taken as the period between the first claim records with HTN and the last claim records due to any reason in 2014.

MPR of the seven AHT drugs was calculated for three different time periods: (1) the first study drug prescription to the last study drug prescription (drug in the first and last prescription need not be same), that is, the first goal (FG) to the last goal (LG); (2) the first study drug prescription to the last other AHT drug (an AHT drug that is not included in this study) prescription, that is, FG to the last random (LR); and (3) the first other AHT drug prescription to the last other AHT drug prescription, that is, the first random (FR) to LR. Treatment adherence was considered very low, low, intermediate, and high corresponding to MPR values $<0.3,0.3$ to $<0.5$, 0.5 to $<0.8$, and $\geq 0.8$, respectively. ${ }^{12,36}$

\section{Statistical Analysis}

All the analyses were performed using statistical analysis software (SAS) 9.3 version. Descriptive analysis was used for continuous variables: mean, $\mathrm{SD}$, standard error (SE) and categorical variables: frequency tables: absolute and relative frequencies. MPR for FG-LR was categorized in ranges of $0 \leq \mathrm{MPR}<0.3, \quad 0.3 \leq \mathrm{MPR}<0.5, \quad 0.5 \leq \mathrm{MPR}<0.8, \quad$ and $0.8 \leq \mathrm{MPR}<1$. MPR was analyzed using descriptive statistics, 
whereas factors affecting MPR were analyzed using multivariate regression analysis. Analysis of covariance was used to evaluate variation in MPR values among AHT drugs. $P$-value of $<0.05$ was considered significant.

\section{Results}

\section{Study Population}

Out of 64,576 patients included in the analysis, the proportion of patients in $>40,40-59,60-79$, and $\geq 80$-year age group was $3.3 \%, 35.14 \%, 50.65 \%$, and $10.98 \%$, respectively. Eastern, midland, and western regions contributed $89.46 \%, 3.95 \%$, and $6.59 \%$ of the study population. Of the included patients, $46.19 \%$ were from municipalities and $36.80 \%$ were from provincial capitals. The average observation duration was 290 days for all the study drugs.

Table 1 presents baseline characteristics and demographics data of patients with HTN for individual AHT drug included. The highest number of patients were receiving amlodipine (33.98\%), whereas the least number of patients were taking valsartan/amlodipine FDC (1.60\%). Patients receiving metoprolol were the oldest among all groups (mean age, 64.85 years). Comorbidities were present in $63.01 \%$ of the patients included in the analysis with highest proportion observed in patients receiving nifedipine GITs $(76.14 \%)$ and lowest among those receiving amlodipine (53.09\%).

\section{MPR of AHT Drugs}

Among all the analysis groups, nifedipine GITs treatment was associated with the highest mean MPR (0.61), whereas metoprolol had the lowest (0.19). MPR values of the study AHT drugs are given in Figure 2A. The difference observed in the mean MPR values for different AHT drugs was significant $(P<0.0001)$. MPR of AHT drugs based on gender, age, city level, hospital tiers, comorbidities, and hospitalization status are presented in the Supplementary Table.

The proportions of patients with $\geq 0.5$ MPR were shown in Figure 2B. Nifedipine GITs-treated patients had the highest proportion of MPR $\geq 0.5$ (60.44\%); whereas metoprololtreated patients had the least proportion (11.31\%). Metoprolol group had highest proportion of patients with very low treatment adherence, ie, MPR $<0.3$ (78.21\%), whereas nifedipine had highest proportion of patients with high treatment adherence, ie, MPR $\geq 0.8(40.85 \%)$, as depicted in Figure 2C.

\section{Use of AHT Drugs}

The proportion of patients receiving combination of AHT drugs was $56.27 \%$. Among the patients included in the study, $60.86 \%$ had replacement of study drug during the observation period. The data of AHT drug usage among the study population and the associated daily cost are

Table I Baseline and Comorbidity Characteristics of Different Antihypertensive Drugs

\begin{tabular}{|l|l|l|l|l|l|l|l|}
\hline & Benazepril & $\begin{array}{l}\text { Nifedipine } \\
\text { GITs }\end{array}$ & Amlodipine & Metoprolol & Valsartan & Indapamide & $\begin{array}{l}\text { Valsartan/ } \\
\text { Amlodipine }\end{array}$ \\
\hline $\begin{array}{l}\text { No. of patients (N) } \\
\text { Primary diagnosis with HTN } \\
\text { (\% of n) }\end{array}$ & 3778 & 11,077 & 21,945 & 16,170 & 8910 & 1661 & 1035 \\
Patients with primary HTN & 96.48 & 97.73 & 97.02 & 96.56 & 97.03 & 96.63 & 95.46 \\
Patients with secondary HTN & 1.11 & 0.48 & 2.09 & 2.12 & 1.54 & 1.51 & 3.48 \\
Secondary diagnosis with HTN & 2.41 & 1.79 & 0.89 & 1.32 & 1.43 & 1.86 & 1.06 \\
(\% of N) & & & & & & \\
Mean observation duration & 291.56 & 295.45 & 290.55 & 293.65 & 291.38 & 293.65 & 289.25 \\
(days) & & & & & & \\
Men (\% of N) & 55.11 & 50.75 & 49.45 & 50.96 & 50.62 & 52.68 & 52.56 \\
Women (\% of N) & 44.89 & 49.25 & 50.55 & 49.04 & 49.38 & 47.32 & 47.44 \\
Mean age (years) & 63.12 & 63.08 & 63.80 & 64.85 & 62.44 & 64.21 & 62.29 \\
\hline *Comorbidities (\% of N) & 66.91 & 76.14 & 53.09 & 64.85 & 63.45 & 56.35 & 60.29 \\
Coronary heart disease & 48.91 & 60.96 & 35.77 & 52.58 & 45.44 & 40.28 & 39.23 \\
Diabetes mellitus & 39.89 & 43.83 & 27.86 & 28.67 & 35.16 & 31.13 & 32.75 \\
Stroke & 13.76 & 17.58 & 10.76 & 11.68 & 11.95 & 12.52 & 11.79 \\
Chronic renal diseases & 3.26 & 3.85 & 2.24 & 2.54 & 3.31 & 1.69 & 4.35 \\
Peripheral vascular disease & 0.82 & 1.27 & 0.52 & 0.72 & 0.79 & 0.66 & 0.97 \\
\hline
\end{tabular}

Note: *Some patients have more than one comorbidity.

Abbreviations: HTN, hypertension; GITs, gastrointestinal tablets. 

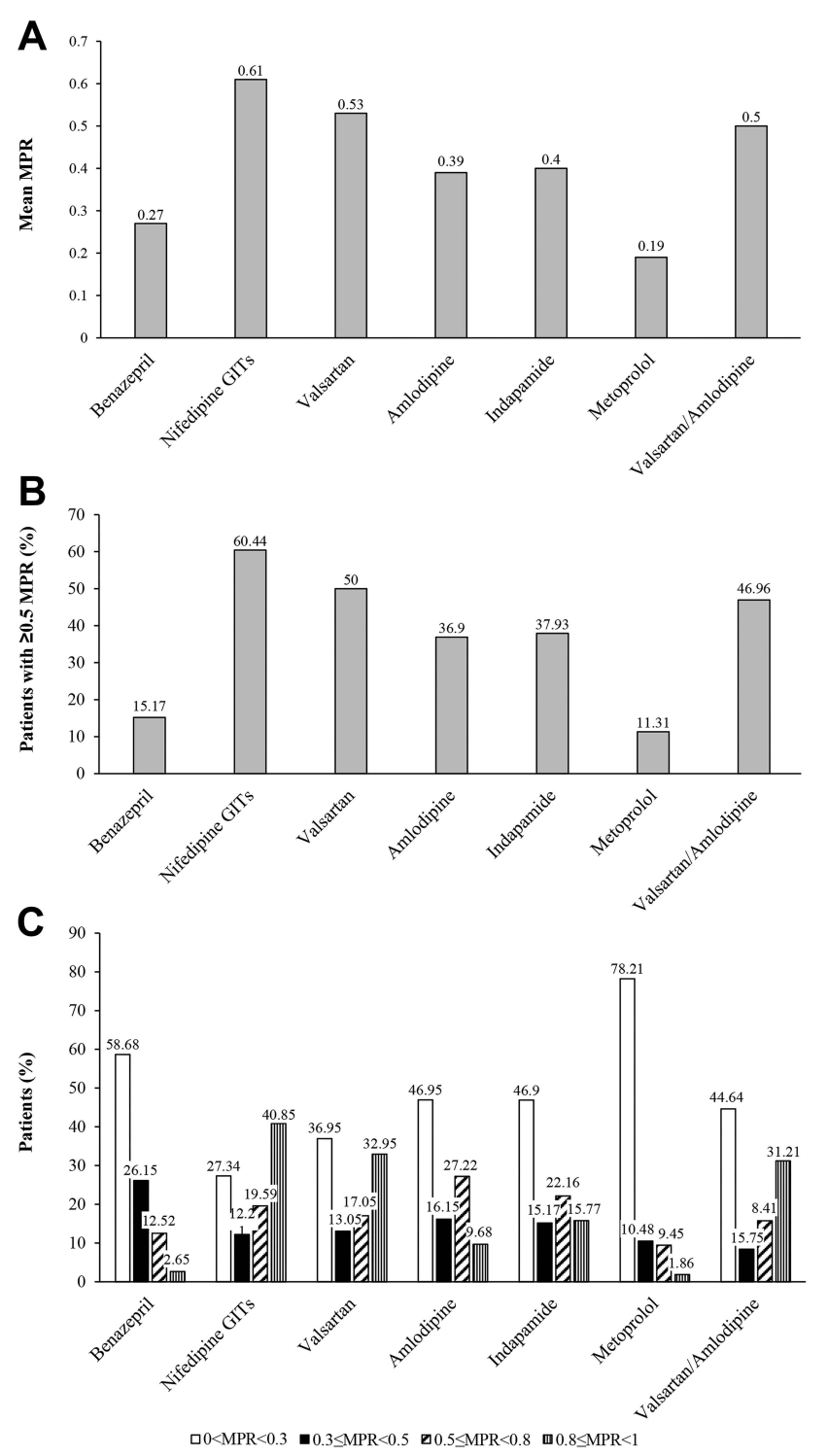

Figure 2 MPR of different AHT drugs. (A) Mean MPR values; (B) percentage of population with MPR of $\geq 0.5$; (C) population distribution among different range of MPR of AHT drugs. The difference among groups was statistically significant for mean MPR and proportion of patients with $\geq 0.5$ MPR $(P<0.000$ I for both). Abbreviations: MPR, medicine possession ratio; GITs, gastrointestinal tablets.

provided in Table 2. Proportion of patients switching to an AHT drug other than those included in this study was least in valsartan/amlodipine FDC group (30.14\%) and highest in metoprolol group (46.00\%), (Table 2). Among AHT drugs, indapamide had the least daily cost (0.93 yuan), whereas valsartan/amlodipine FDC had the highest daily cost $(8.7$ yuan).

\section{Outpatient Visit}

The number of annual per capita outpatient visit was highest for Nifedipine GITs (32.6) and lowest for valsartan/ amlodipine FDC (19.73). Approximately 45.02\% of patients with HTN visited the tier 1 hospitals and grassroot community units followed by tier 3 hospitals $(35.82 \%)$, tier 2 hospitals $(16.58 \%)$, and pharmacies $(2.44 \%)$, with $0.14 \%$ of patients visiting unknown medical institutions. Table 3 presents hospital visit data of patients as per the prescribed AHT drug.

\section{Potential Factors Affecting MPR of AHT Drugs}

Factors that could have modulated MPR were evaluated using stepwise regression based on a multivariate linear regression model. The results showed that MPR was positively affected $(P<0.0001$ for all comparisons) by following variables: (1) age, (2) city level, (3) comorbidities (diabetes, stroke), (4) prescription of multidrug combination, (5) tier 3 hospital visits, (6) reimbursement ratio, (7) study drugs, except metoprolol, in the first prescription (Table 4). Presence of coronary artery disease (SE, $0.003 ; P=0.0016$ ), times of hospitalization (SE, 0.0030; $P<0.0001$ ), and metoprolol prescription (SE, 0.0068; $P<0.0001)$ negatively affected MPR (Table 4).

\section{Discussion}

Research on AHT treatment adherence helps understanding the current scenario of treatment adherence, designing interventions, and formulating relevant policies to improve the health outcomes of patients. To the best of our knowledge, this is the first large-scale study to determine treatment adherence for different AHT drugs in China using the CHIRA database. Given the fact that treatment adherence is influenced by demographic, region-specific, organizational, comorbidities, and medication-related variables, we also investigated the association of these factors with the recorded MPR for all AHT drugs included in the study. Our results showed poor overall AHT treatment adherence among Chinese patients with HTN and revealed that they have the highest treatment adherence for nifedipine GITs and the lowest for metoprolol. A positive association of MPR with age, city level, comorbidities, frequency of outpatient visits, and hospitalization was observed.

We used the MPR to evaluate treatment adherence among the study population, which is a globally accepted metric to retrospectively assess treatment adherence. ${ }^{18,37}$ Other measures of treatment adherence include medication-total, adherence ratio, proportion of days covered, refill adherence, compliance rate, compliance ratio, continuous measure of medication acquisition, continuous measure of medication 
Table 2 The Use of the Seven Antihypertensive Drugs Among the Patients

\begin{tabular}{|c|c|c|c|c|c|c|c|}
\hline Variables & $\begin{array}{l}\text { Benazepril } \\
\mathrm{N}=3778\end{array}$ & $\begin{array}{l}\text { Nifedipine } \\
\text { GITs } \\
\mathrm{N}=\text { I I,077 }\end{array}$ & $\begin{array}{l}\text { Amlodipine } \\
\mathrm{N}=21,945\end{array}$ & $\begin{array}{l}\text { Metoprolol } \\
\mathrm{N}=16,170\end{array}$ & $\begin{array}{l}\text { Valsartan } \\
\mathrm{N}=8910\end{array}$ & $\begin{array}{l}\text { Indapamide } \\
\mathrm{N}=1661\end{array}$ & $\begin{array}{l}\text { Valsartan/ } \\
\text { amlodipine } \\
\mathrm{N}=1035\end{array}$ \\
\hline $\begin{array}{l}\text { Proportion of multidrug combination in the first } \\
\text { prescription (\%) }\end{array}$ & 61.83 & 46.06 & 51.52 & 68.92 & 57.12 & 68.27 & 40.19 \\
\hline Proportion of drug replacement (\%) & 62.07 & 61.94 & 51.29 & 63.52 & 61.28 & 77.54 & 48.41 \\
\hline Switching to benazepril (\%) & - & 3.77 & 2.21 & 2.03 & 1.76 & 1.93 & 0.77 \\
\hline $\begin{array}{l}\text { Switching to nifedipine controlled release tablets } \\
\text { (\%) }\end{array}$ & 9.95 & - & 3.80 & 6.64 & 9.58 & 6.26 & 2.51 \\
\hline Switching to amlodipine (\%) & 11.91 & 7.39 & - & 11.21 & 12.29 & 10.05 & 10.63 \\
\hline Switching to metoprolol (\%) & 9.56 & 8.87 & 8.28 & - & 8.73 & 9.39 & 9.47 \\
\hline Switching to valsartan (\%) & 5.11 & 8.01 & 5.12 & 5.05 & - & 5.54 & 8.70 \\
\hline Switching to indapamide (\%) & 1.48 & 1.27 & 0.87 & 1.06 & $0-.94$ & - & 1.06 \\
\hline Switching to valsartan/amlodipine (\%) & 0.00 & 0.50 & 0.76 & 0.76 & 1.04 & 0.84 & - \\
\hline $\begin{array}{l}\text { Switching to antihypertensive drug(s) other than } \\
\text { the seven target drugs (\%) }\end{array}$ & 37.53 & 42.13 & 38.61 & 46.00 & 38.87 & 43.53 & 30.14 \\
\hline Daily cost of antihypertensive drugs (yuan) (\%) & 7.81 & 4.49 & 4.38 & 4.00 & 4.40 & 0.93 & 8.70 \\
\hline
\end{tabular}

Abbreviation: GITs, gastrointestinal tablets.

Table 3 Hospital Visits by Patients Receiving Studied AHT Drugs

\begin{tabular}{|l|l|l|l|l|l|l|l|}
\hline & Benazepril & $\begin{array}{l}\text { Nifedipine } \\
\text { GITs }\end{array}$ & Amlodipine & Metoprolol & Valsartan & Indapamide & $\begin{array}{l}\text { Valsartan/ } \\
\text { amlodipine }\end{array}$ \\
\hline $\begin{array}{l}\text { Annual per capita outpatient visit } \\
\text { (mean) }\end{array}$ & 27.21 & 32.60 & 22.11 & 24.79 & 27.38 & 25.04 & 19.73 \\
\hline $\begin{array}{l}\text { Annual per capita hospital admission } \\
\text { (mean) }\end{array}$ & 0.49 & 0.39 & 0.38 & 0.55 & 0.37 & 0.48 & 0.32 \\
\hline Direction of outpatient flow (\%) & & & & & \\
Tier 3 hospitals & 31.96 & 31.03 & 32.24 & 36.08 & 32.71 & 29.38 & 57.32 \\
Tier 2 hospitals & 16.80 & 15.34 & 15.73 & 18.05 & 15.52 & 19.20 & 15.43 \\
Tier I hospitals & 48.26 & 50.96 & 49.59 & 42.57 & 49.36 & 48.32 & 26.11 \\
Pharmacies & 2.88 & 2.53 & 2.26 & 3.06 & 2.30 & 2.92 & 1.11 \\
Others & 0.10 & 0.14 & 0.18 & 0.23 & 0.11 & 0.18 \\
\hline Direction of inpatient flow (\%) & & & & & & 0.03 \\
Tier 3 hospitals & 54.04 & 59.97 & 56.10 & 56.68 & 58.56 & 50.25 \\
$\quad$ Tier 2 hospitals & 27.08 & 25.68 & 28.83 & 32.31 & 26.22 & 32.13 \\
$\quad \begin{array}{l}\text { Tier I hospitals } \\
\text { Others }\end{array}$ & 18.18 & 13.94 & 13.44 & 9.79 & 13.60 & 15.88 \\
\hline
\end{tabular}

Abbreviation: GITs, gastrointestinal tablets.

gaps, continuous/single interval measure of medication acquisition, and continuous/single interval measure of medication gaps. ${ }^{19}$ However, MPR is the most commonly used measure of treatment adherence. ${ }^{18}$ MPR is used as a continuous variable or with appropriate justification, as a dichotomized variable. ${ }^{18}$ However, it does not take gaps in refills into account and heavily depends on the denominator used during calculations (either number of days elapsed during the period or total study duration). ${ }^{37}$ Hence, the MPR is not useful to evaluate nonadherence in case of premature terminations and gap in refilling. ${ }^{37}$ In spite of these limitations, MPR has been used in various studies to assess treatment adherence as it is easy to calculate and interpret. ${ }^{18,19}$ Previous studies have shown that the type of AHT drug prescribed significantly affects treatment adherence and persistence. ${ }^{38-43}$ Among AHT agents, ACE inhibitors and CCBs are reported to have better treatment adherence and persistence compared with diuretics and $\beta$-blockers. ${ }^{38-43}$ In a study carried out in Italian 
Table 4 Factors Affecting MPR. Results of Multivariate Regression Analysis

\begin{tabular}{|c|c|c|c|c|}
\hline Variables & Parameter estimation & Standard error & $\mathbf{T}$ value & P-value \\
\hline Gender (male patients as control) & -0.0046 & 0.0024 & -1.9 & 0.0573 \\
\hline \multicolumn{5}{|l|}{ Age ( $\leq 40$ years as control) } \\
\hline $4 I-60$ years & 0.0776 & 0.0068 & $\mathrm{II} .44$ & $<0.0001$ \\
\hline $6 I-80$ years & 0.0999 & 0.0068 & 14.73 & $<0.0001$ \\
\hline$\geq 81$ years & 0.0912 & 0.0078 & 11.75 & $<0.0001$ \\
\hline \multicolumn{5}{|l|}{ City level (prefecture level as control) } \\
\hline Municipalities & 0.0746 & 0.0042 & 17.72 & $<0.0001$ \\
\hline Provincial capital & 0.0040 & 0.0043 & 0.93 & 0.3516 \\
\hline \multicolumn{5}{|l|}{ Comorbidities } \\
\hline Diabetes & 0.0330 & 0.0027 & 12.18 & $<0.0001$ \\
\hline Stroke & 0.0112 & 0.0038 & 2.92 & 0.0035 \\
\hline Coronary artery disease & -0.0095 & 0.0030 & -3.15 & 0.0016 \\
\hline Chronic renal diseases & 0.0134 & 0.0074 & 1.81 & 0.0701 \\
\hline Peripheral vascular diseases & 0.0215 & 0.0141 & 1.52 & 0.1290 \\
\hline Multidrug combination vs monotherapy & 0.0221 & 0.0029 & 7.7 & $<0.0001$ \\
\hline Visit to tertiary hospital & 0.0821 & 0.0031 & 26.05 & $<0.0001$ \\
\hline Number of hospitalizations & -0.0402 & 0.0030 & -13.4 & $<0.0001$ \\
\hline Average reimbursement ratio & 0.1151 & 0.0042 & 27.05 & $<0.0001$ \\
\hline \multicolumn{5}{|c|}{ Drug in the first prescription (benazepril alone as control) } \\
\hline Nifedipine GITs & 0.2829 & 0.0069 & 41.05 & $<0.0001$ \\
\hline Amlodipine & 0.1359 & 0.0065 & 20.78 & $<0.0001$ \\
\hline Metoprolol & -0.1126 & 0.0068 & -16.46 & $<0.0001$ \\
\hline Valsartan & 0.2553 & 0.0072 & 35.38 & $<0.0001$ \\
\hline Indapamide & 0.1024 & 0.0109 & 9.41 & $<0.0001$ \\
\hline Valsartan/amlodipine FDC & 0.2327 & 0.0118 & 19.74 & $<0.0001$ \\
\hline Combination of two or more drugs & 0.2825 & 0.0073 & 38.42 & $<0.0001$ \\
\hline
\end{tabular}

Abbreviations: FDC, fixed-dose combination; GITs, gastrointestinal tablets.

patients with HTN, it revealed a higher continuation rate in patients treated with ACE inhibitors (23.2\%), ARBs (25.2\%), and CCBs $(23.9 \%)$ than in those treated with $\beta$-blockers and diuretics (11.2-11.8\%). ${ }^{39}$ Mancia et al have reported that the risk of discontinuation of AHT treatment was the lowest for ARBs (HR, 0.3; 95\%CI, 0.29- 0.30], followed by ACE inhibitors (HR, 0.35; 95\%CI, 0.51-0.53), CCBs (HR, 0.52; 95\% CI, 0.51-0.53), and $\beta$-blockers (HR, 0.5; 95\%CI, 0.53-0.55) compared with diuretics. ${ }^{44}$ Our results showing the highest treatment adherence for nifedipine GITs, and least treatment adherence for metoprolol, are in line with these previous observations.

Although replacement rate of drug was high in the indapamide group, treatment adherence for it was comparable to other classes of AHT drugs (Figure 2A-C). This is in contrast with the findings of Schulz et al, who reported the highest nonadherence for diuretics $(66.3 \%)$ and the lowest for $\beta$-blockers $(55.2 \%){ }^{22}$ We speculate lower daily cost for indapamide treatment might have positively affected the adherence of patients with HTN to it.

In addition, our results showed that treatment adherence for AHT drugs is significantly affected by the level of the city with better adherence observed in patients receiving treatment in municipalities. The impact of city level on patients' adherence might be due to cost-efficient management services provided including health records, regular follow-ups and health education ${ }^{45,46}$ as reported by a survey showing significant association between community management and AHT treatment adherence. ${ }^{47}$ Furthermore, in our study, older age and presence of comorbidity positively affected treatment adherence, which is in line with the results of a study by Schulz et al showing lower nonadherence to AHT drugs in older patients (aged $\geq 65$ years) than younger patients, ${ }^{22}$ and other studies. $^{48,49}$ This highlights the need to improve health care for the younger population. In addition, our study showed lower adherence of females to treatment which is 
in contrast with the findings of Wong et al. ${ }^{29}$ Results from the China Health and Nutrition survey, which reported increased chances of receiving treatment $(28.7 \%$; 95\%CI, 10.6- 46.7) among patients with health insurance also support our results showing the positive effect of the reimbursement ratio on AHT drug compliance. ${ }^{50}$

The strength of our study lies in the use of real-world data for the analysis, large sample size, and the accuracy of information available in the CHIRA database.

Our study had a few limitations. First, this was a retrospective study and so there are chances of bias in data selection and analysis. Second, the duration of this study was short, ie, one year due to which the treatment adherence observed could be higher than that of a study with longer duration. Third, $91.5 \%$ of the population included in the analysis was from the eastern region of China. Hence, the generalizability of these results to patients from central and western regions of China is limited. The analysis of treatment adherence was based on prescription information, and therefore, whether the drugs prescribed were consumed or not by the patients stays unclear. Hence, results should be interpreted carefully as there are chances of under- or overestimation of treatment adherence. Fourth, we could not evaluate the effect of treatment adherence on blood pressure control rate and health outcomes as the CHIRA database did not reflect information in this regard. Fifth, DDD was not suitable for MPR estimation of $\beta$-blockers. Finally, we did not examine other factors that can influence treatment adherence, such as social support, socioeconomic status of patients, and reminders for medicine intake.

\section{Conclusion}

Our results showed poor overall AHT treatment adherence among Chinese patients with HTN. Better reimbursement ratio, use of combination therapy and prescribing effective long-acting AHT drugs will help to improve treatment adherence, and hence HTN management, in China.

\section{Ethics Approval and Informed Consent}

The data from CHIRA database is available upon payment. As the study used patients deidentified data available from the CHIRA database, the study was exempted from Biomedical Ethics Committee of Peking University IRB approval with IRB communication no. IRB0000105217012.

\section{Acknowledgments}

The authors acknowledge Brainpower Medical Consulting Ltd, China, for data management. They also acknowledge Dr Satya Lavanya Jakki and Dr Amit Bhat (Indegene, Bangalore, India) for providing medical writing support and technical assistance in the development of this manuscript.

\section{Author Contributions}

All authors contributed to data analysis, drafting or revising the article, gave final approval of the version to be published, and agree to be accountable for all aspects of the work.

\section{Funding}

This study was funded by Bayer.

\section{Disclosure}

Shanshan Li, Hua Xiao and Zhitao Liu are employees of Bayer Healthcare Company Limited (China). The authors declare that they have no other possible conflicts of interest in this work.

\section{References}

1. Forouzanfar MH, Liu P, Roth GA, et al. Global burden of hypertension and systolic blood pressure of at least 110 to $115 \mathrm{~mm} \mathrm{Hg}, 1990-2015$. JAMA. 2017;317(2):165-182. doi:10.1001/jama.2016.19043

2. Gakidou E, Afshin A, Abajobir AA, et al. Global, regional, and national comparative risk assessment of 84 behavioural, environmental and occupational, and metabolic risks or clusters of risks, 1990-2016: a systematic analysis for the global burden of disease study 2016 . Lancet. 2017;390(10100):1345-1422. doi:10.1016/S0140-6736(17) 32366-8

3. Forouzanfar MH, Afshin A, Alexander LT, GBD 2015 Risk Factors Collaborators. Global, regional, and national comparative risk assessment of 79 behavioural, environmental and occupational, and metabolic risks or clusters of risks, 1990-2015: a systematic analysis for the global burden of disease study 2015. Lancet. 2016;388 (10053):1659-1724. doi:10.1016/S0140-6736(16)31679-8

4. Wang Z, Chen Z, Zhang L, et al. Status of hypertension in China: results from the China hypertension survey, 2012-2015. Circulation. 2018;137 (22):2344-2356. doi:10.1161/CIRCULATIONAHA.117.032380

5. Mancia G, Messerli F, Bakris G, Zhou Q, Champion A, Pepine CJ. Blood pressure control and improved cardiovascular outcomes in the international verapamil SR-trandolapril study. Hypertension. 2007;50 (2):299-305. doi:10.1161/HYPERTENSIONAHA.107.090290

6. Lee JH, Kim S-H, Kang S-H, et al. Blood pressure control and cardiovascular outcomes: real-world implications of the $2017 \mathrm{ACC} /$ AHA hypertension guideline. Sci Rep. 2018;8(1):13155. doi:10.1038/ s41598-018-31549-5

7. Mancia G, Fagard R, Narkiewicz K, et al. 2013 ESH/ESC guidelines for the management of arterial hypertension: the task force for the management of arterial hypertension of the European Society of Hypertension (ESH) and of the European Society of Cardiology (ESC). J Hypertens. 2013;31(7):1281-1357. doi:10.1097/01.hjh.00 00431740.32696.cc 
8. Laurent S. Antihypertensive drugs. Pharmacol Res. 2017;124:116-125. doi:10.1016/j.phrs.2017.07.026

9. James PA, Oparil S, Carter BL, et al. 2014 Evidence-based guideline for the management of high blood pressure in adults: report from the panel members appointed to the eighth joint national committee (JNC 8). JAMA. 2014;311(5):507. doi:10.1001/jama.2013.284427

10. Go AS, Bauman MA, Coleman King SM, et al. An effective approach to high blood pressure control: a science advisory from the American Heart Association, the American College of Cardiology, and the centers for disease control and prevention. Hypertension. 2014;63(4):878-885. doi:10.1161/HYP.0000000000000003

11. Yiannakopoulou E, Papadopulos JS, Cokkinos DV, Mountokalakis TD. Adherence to antihypertensive treatment: a critical factor for blood pressure control. Eur J Cardiovasc Prev Rehabil. 2005;12(3):243-249. doi:10.1097/00149831-200506000-00010

12. Lee HJ, Jang S-I, Park E-C. Effect of adherence to antihypertensive medication on stroke incidence in patients with hypertension: a population-based retrospective cohort study. BMJ Open. 2017;7(6): e014486. doi:10.1136/bmjopen-2016-014486

13. Brown MT, Bussell JK. Medication adherence: WHO cares? Mayo Clin Proc. 2011;86(4):304-314. doi:10.4065/mcp.2010.0575

14. Vrijens B, Antoniou S, Burnier M, de la Sierra A, Volpe M. Current situation of medication adherence in hypertension. Front Pharmacol. 2017;8:100. doi:10.3389/fphar.2017.00100

15. Sabaté E, World Health Organization, editors. Adherence to LongTerm Therapies: Evidence for Action. Geneva: World Health Organization; 2003. 198.

16. Ambaw AD, Alemie GA, Yohannes SM, Mengesha ZB. Adherence to antihypertensive treatment and associated factors among patients on follow up at University of Gondar Hospital, Northwest Ethiopia. BMC Public Health. 2012;12(1):282. doi:10.1186/1471-2458-12-282

17. Lima-Dellamora ED, Osorio-de-Castro CG, Madruga LG, et al. Use of pharmacy records to measure treatment adherence: a critical review of the literature. Cad Saude Publica. 2017;33(3):e00136216.

18. Andrade SE, Kahler KH, Frech F, Chan KA. Methods for evaluation of medication adherence and persistence using automated databases. Pharmacoepidemiol Drug Saf. 2006;15(8):565-574. doi:10.1002/ pds. 1230

19. Lam WY, Fresco P. Medication adherence measures: an overview. Biomed Res Int. 2015;2015:217047. doi:10.1155/2015/217047

20. Sung S-K, Lee S-G, Lee K-S, Kim D-S, Kim K-H, Kim K-Y. First-year treatment adherence among outpatients initiating antihypertensive medication in Korea: results of a retrospective claims review. Clin Ther. 2009;31(6):1309-1320. doi:10.1016/j.clinthera.2009.06.011

21. Han E, Suh D-C, Lee S-M, Jang S. The impact of medication adherence on health outcomes for chronic metabolic diseases: a retrospective cohort study. Res Soc Adm Pharm. 2014;10(6):e8798. doi:10.1016/j.sapharm.2014.02.001

22. Schulz M, Krueger K, Schuessel K, et al. Medication adherence and persistence according to different antihypertensive drug classes: a retrospective cohort study of 255,500 patients. Int $J$ Cardiol. 2016;220:668-676. doi:10.1016/j.ijcard.2016.06.263

23. Johnsrud M,W, Schafermeyer K. Measuring adherence and persistence in drug therapy. JMCP. 2002;8(3):205-206. doi:10.18553/ jmcp.2002.8.3.204

24. Raghupathi W, Raghupathi V. Big data analytics in healthcare: promise and potential. Health Inf Sci Syst. 2014;2(1):3. doi:10.1186/ 2047-2501-2-3

25. Wong MCS, Jiang JY, Griffiths SM. Antihypertensive drug adherence among 6408 Chinese patients on angiotensin-converting enzyme inhibitors in Hong Kong: a cohort study. $J$ Clin Pharmacol. 2010;50(5):598-605. doi:10.1177/0091270009346058

26. Piercefield EW, Howard ME, Robinson MH, Kirk CE, Ragan AP, Reese SD. Antihypertensive medication adherence and blood pressure control among central Alabama veterans. J Clin Hypertens. 2017;19(5):543-549. doi:10.1111/jch.12953
27. Tsiantou V, Pantzou P, Pavi E, Koulierakis G, Kyriopoulos J. Factors affecting adherence to antihypertensive medication in Greece: results from a qualitative study. Patient Prefer Adherence. 2010;7 (4):335-343. doi:10.2147/PPA.S12326

28. Tilea I, Petra D, Voidazan S, Ardeleanu E, Varga A. Treatment adherence among adult hypertensive patients: a cross-sectional retrospective study in primary care in Romania. Patient Prefer Adherence. 2018;24(12):625-635. doi:10.2147/PPA.S162965

29. Wong MCS, Jiang JY, Griffiths SM. Factors associated with antihypertensive drug compliance in 83,884 Chinese patients: a cohort study. J Epidemiol Community Health. 2010;64(10):895-901. doi:10. 1136/jech.2009.091603

30. Brown MJ. Hypertension and ethnic group. BMJ. 2006;332 (7545):833-836. doi:10.1136/bmj.332.7545.833

31. van Wijk BLG, Shrank WH, Klungel OH, Schneeweiss S, Brookhart MA, Avorn J. A cross-national study of the persistence of antihypertensive medication use in the elderly. J Hypertens. 2008;26(1):145-153. doi:10.1097/HJH.0b013e32826308b4

32. Public Policy Committee. International Society of Pharmacoepidemiology. Guidelines for good pharmacoepidemiology practice (GPP): guidelines for good pharmacoepidemiology practice Pharmacoepidemiol Drug Saf. 2016;25(1):2-10. doi:10.1002/pds.3891.

33. Swart E, Gothe H, Geyer S, et al. Gute Praxis Sekundärdatenanalyse (GPS): leitlinien und Empfehlungen. Gesundheitswesen. 2015;77 (02):120-126. doi:10.1055/s-0034-1396815

34. The European Network of Centres for Pharmacoepidemiology and Pharmacovigilance (ENCePP). Guide on Methodological Standards in Pharmacoepidemiology (Revision 7). 2018. EMA/95098/2010.

35. de Kraker MEA, Abbas M, Huttner B, Harbarth S. Good epidemiological practice: a narrative review of appropriate scientific methods to evaluate the impact of antimicrobial stewardship interventions. Clin Microbiol Infect. 2017;23(11):819-825. doi:10.1016/j.cmi.2017.05.019

36. Krousel-Wood M, Holt E, Joyce C, et al. Differences in cardiovascular disease risk when antihypertensive medication adherence is assessed by pharmacy fill versus self-report. J Hypertens. 2015;33 (2):412-420. doi:10.1097/HJH.0000000000000382

37. Fairman KA, Matheral B. Evaluating medication adherence: which measure is right for your program? J Manag Care Spec Pharm. 2000;6(6):499-506.

38. Burke TA, Sturkenboom MC, Lu S, Wentworth CE, Lin Y, Rhoads GG. Discontinuation of antihypertensive drugs among newly diagnosed hypertensive patients in UK general practice. J Hypertens. 2006;24(6):1193-1200. doi:10.1097/01.hjh.0000226211.95936.f5

39. Mazzaglia G, Mantovani LG, Sturkenboom MCJM, et al. Patterns of persistence with antihypertensive medications in newly diagnosed hypertensive patients in Italy: a retrospective cohort study in primary care. J Hypertens. 2005;23(11):2093-2100. doi:10.1097/01.hjh.000 $0186832.41125 .8 \mathrm{a}$

40. Hasford J, Mimran A, Simons WR. A population-based European cohort study of persistence in newly diagnosed hypertensive patients. J Hum Hypertens. 2002;16(8):569-575. doi:10.1038/sj.jhh.1001451

41. Elliott WJ, Plauschinat CA, Skrepnek GH, Gause D. Persistence, adherence, and risk of discontinuation associated with commonly prescribed antihypertensive drug monotherapies. $J$ Am Board Fam Med. 2007;20(1):72-80. doi:10.3122/jabfm.2007.01.060094

42. Payne KA, Esmonde-White S. Observational studies of antihypertensive medication use and compliance: is drug choice a factor in treatment adherence? Curr Hypertens Rep. 2000;2(6):515-524. doi:10.1007/s11906-996-0035-6

43. Marentette MA, Gerth WC, Billings DK, Zarnke KB. Antihypertensive persistence and drug class. Can $J$ Cardiol. 2002;18(6):649-656

44. Mancia G, Zambon A, Soranna D, Merlino L, Corrao G. Factors involved in the discontinuation of antihypertensive drug therapy: an analysis from real life data. J Hypertens. 2014;32(8):1708-1715. doi:10.1097/HJH.0000000000000222. 
45. Maimaris W, Paty J, Perel P, et al. The influence of health systems on hypertension awareness, treatment, and control: a systematic literature review. PLoS Med. Caulfield MJ, editor. 2013;10(7):e1001490. doi:10.1371/journal.pmed.1001490.

46. Li Y, Wang JL, Zhang XC, et al. Effectiveness of adherence to standardized hypertension management by primary health care workers in China: a cross-sectional survey 3 years after the healthcare reform. Biomed Environ Sci BES. 2016;29(12):915-921. doi:10.3967/ bes2016.123

47. Zhang Y, Li X, Mao L, et al. Factors affecting medication adherence in community-managed patients with hypertension based on the principal component analysis: evidence from Xinjiang, China. Patient Prefer Adherence. 2018;12:803-812. doi:10.2147/PPA. S158662
48. Krueger K, Botermann L, Schorr SG, Griese-Mammen N, Laufs U, Schulz M. Age-related medication adherence in patients with chronic heart failure: a systematic literature review. Int $J$ Cardiol. 2015;1 (184):728-735. doi:10.1016/j.ijcard.2015.03.042

49. Basheti IA, Hait SSE, Qunaibi EA, Aburuz S, Bulatova N. Associations between patient factors and medication adherence: a Jordanian experience. Pharm Pract. 2016;14(1):639. doi:10. 18549/PharmPract.2016.01.639

50. Liao Y, Gilmour S, Shibuya K, Kokubo Y. Health insurance coverage and hypertension control in China: results from the China health and nutrition survey. PLoS One. 2016;11(3):e0152091. doi:10.1371/journal.pone. 0152091

\section{Publish your work in this journal}

Patient Preference and Adherence is an international, peer-reviewed, open access journal that focuses on the growing importance of patient preference and adherence throughout the therapeutic continuum. Patient satisfaction, acceptability, quality of life, compliance, persistence and their role in developing new therapeutic modalities and compounds to optimize clinical outcomes for existing disease states are major areas of interest for the journal. This journal has been accepted for indexing on PubMed Central. The manuscript management system is completely online and includes a very quick and fair peer-review system, which is all easy to use. Visit http:// www.dovepress.com/testimonials.php to read real quotes from published authors. 